\title{
Impact of the COVID-19 pandemic on orthopedic fracture characteristics in three hospitals in Turkey: A multi-center epidemiological study
}

\author{
Sinan Oguzkaya ${ }^{1}$, Abdulhamit Misir ${ }^{2}$, Mustafa Ozcamdalli²(D), Gokay Eken ${ }^{\circledR}$, Turan Bilge Kizkapan ${ }^{4}(\mathbb{D}$, \\ Muhammed Bilal Kurk² ${ }^{\mathbb{D}}$, Erdal Uzun ${ }^{5}$ D \\ ${ }^{1}$ Department of Orthopedics and Traumatology, Sarkışla State Hospital, Sivas, Turkey \\ ${ }^{2}$ Department of Orthopedics and Traumatology, Başaksehir Çam and Sakura City Hospital, Istanbul, Turkey, \\ ${ }^{3}$ Department of Orthopedics and Traumatology, Bursa Acıbadem Hospital, Bursa, Turkey \\ ${ }^{4}$ Department of Orthopedics and Traumatology, Çekirge State Hospital, Bursa, Turkey \\ ${ }^{5}$ Department of Orthopedics and Traumatology, Erciyes University School of Medicine, Kayseri, Turkey
}

Novel coronavirus disease-2019 (COVID-19) was first reported in Wuhan ${ }^{[1]}$ and spread throughout the world within several months. The World Health Organization (WHO) declared the COVID-19 outbreak as a pandemic on March $11^{\text {th }}, 2020 .^{[2]}$ In Turkey, the first confirmed COVID-19 case was reported on March $10^{\text {th }}, 2020 .^{[3]}$

As in many other countries, all elective surgeries were canceled in Turkey to control the nosocomial spread of disease and to not exhaust healthcare resources. ${ }^{[4]}$ Lockdown changed daily life habits and working facilities and practices. ${ }^{[5]}$ Therefore, the

Received: January 05, 2021

Accepted: March 12, 2021

Published online: June 11, 2021

Correspondence: Sinan Oguzkaya, MD. Sarkışla Devlet Hastanesi Ortopedi ve Travmatoloji Kliniği, 58400 Sarkışla, Sivas, Türkiye.

E-mail: sinanoguzkaya@hotmail.com

Doi: $10.52312 /$ jdrs. 2021.2

Citation: Oguzkaya S, Misir A, Ozcamdalli M, Eken G, Kizkapan TB, Kurk MB, Uzun E. Impact of the COVID-19 pandemic on orthopedic fracture characteristics in three hospitals in Turkey: A multi-center epidemiological study. Jt Dis Relat Surg 2021;32(2):323-332.

(O2021 All right reserved by the Turkish Joint Diseases Foundation

This is an open access article under the terms of the Creative Commons Attribution-NonCommercial License, which permits use, distribution and reproduction in any medium, provided the original work is properly cited and is not used for commercial purposes (http://creativecommons.org/licenses/by-nc/4.0/).

\section{ABSTRACT}

Objectives: The aim of this study was to evaluate the impact of novel coronavirus-2019 (COVID-19) on the epidemiological characteristics of orthopedic fractures.

Patients and methods: A total of 2,960 patients (1,755 males, 1,205 females; mean age: 39.6 years; range, 1 to 98 years) with orthopedic fractures were included in the study: 552 patients during the pandemic period (March $10^{\text {th }}$ and July $1^{\text {st }}, 2020$ ) and 1,158 control patients in the same period 2019 and 1,250 control patients in 2018. Epidemiological characteristics, injury mechanisms, fracture locations and treatment details of the patients were analyzed and compared between 2018, 2019 and 2020 for adult and pediatric populations.

Results: Of a total of 552 patients, 485 were adults and 67 were pediatric patients. In the control groups, of 1,158 patients (2019), 770 were adults and 378 were pediatric patients and, of 1,250 patients (2018), 857 were adults and 393 were pediatric patients. The proportion of proximal femur and hand fractures significantly increased during the pandemic period $(\mathrm{p}=0.025$ and $\mathrm{p}=0.038$, respectively). The most frequent surgical indication in the pandemic period was proximal femoral fracture. The proportion of home accidents as an injury mechanism significantly increased in the pandemic period compared to 2018 and 2019 (48.5\% vs. $18.6 \%$ and $20.6 \%$, respectively; $\mathrm{p}=0.000$ ). The proportion of female pediatric patients significantly increased during the pandemic period compared to 2018 and 2019 (44.8\% vs. $25.4 \%$ and $27.2 \%$, respectively, $\mathrm{p}=0.004)$. The proportion of forearm fractures $(\mathrm{p}=0.001)$ also increased, and the proportion of tibia-fibula fractures $(p=0.03)$ decreased. The most frequent surgical indication in pediatric patients was distal humeral fracture in both groups.

Conclusion: During the pandemic period, proximal femoral fractures in the elderly remained a concern. In-home preventative strategies may be beneficial to reduce the incidence of hip fractures in the elderly.

Keywords: COVID-19, epidemiology, fracture, orthopedic, pandemic, trauma. 
number of patients who were admitted to orthopedic surgery decreased. ${ }^{[6]}$ In addition, the epidemiological characteristics of the fractures changed during the outbreak period. ${ }^{[7]}$

Due to imposed restrictions, it can be expected that motor vehicle accidents, industrial accidents, and sports traumas may decrease during the pandemic. Conversely, many individuals started to have indoor activities during the outbreak period, and unfamiliar activities may increase the risk of home accidents. Decreased social life activities, reduced mobility, restrictions for traveling and outdoor sport activities, lockdown and reduced sunlight exposure may cause osteoporosis in the elderly population, which is a significant risk factor for fragility fractures. ${ }^{[8,9]}$ Also, fear of visiting hospital may interrupt regular osteoporosis treatment. ${ }^{[10]}$ At the time of the writing of this article, there has been only one single-center Turkish study published about the epidemiological characteristics of orthopedic fractures during the pandemic period. ${ }^{[11]} \mathrm{Lv}$ et al. ${ }^{[7]}$ recently published a multi-center, comparative study reporting a proportional increase in osteoporotic fractures. This is the first multi-center study regarding the impact of the COVID-19 pandemic on orthopedic fracture characteristics in Turkey.

In this study, we hypothesized that the distribution of the fracture characteristics would change in the pandemic period and the proportion of osteoporotic fractures caused by minor trauma would increase compared to that in the previous years. We, therefore, aimed to evaluate the epidemiological characteristics of orthopedic fractures during the outbreak period.

\section{PATIENTS AND METHODS}

This multi-center, retrospective, epidemiological study was conducted at three healthcare centers of Turkey (Kırşehir Ahi Evran University Training and Research Hospital, Bursa Çekirge State Hospital and Sivas Sarkışla State Hospital) between August 2020 and December 2020. All patients admitted for orthopedic fractures were screened. Inclusion criteria were as follows: acute orthopedic fractures admitted to the emergency department or orthopedics and traumatology outpatient clinic, and time of injury from March $10^{\text {th }}$ to July $1^{\text {st }}, 2020$, or from March $10^{\text {th }}$ to July $1^{\text {st }}, 2019$, and 2018. The first COVID-19 case was reported in Turkey on March $10^{\text {th }}, 2020$, the Turkish Government declared the start of the normalization process and on July $1^{\text {st }}, 2020$. Exclusion criteria were as follows: pathological fractures, pure dislocations, and incomplete medical records. The fractures were searched from archives based on the International Classification of Diseases $10^{\text {th }}$ Revision (ICD-10) codes. The presence of fractures was confirmed using radiological records from the Picture Archiving Communication Systems. After confirmation of the fracture, demographic data were obtained from the patient files. The remaining data were collected through phone interviews of the patients or their relatives. The study protocol was approved by the Kirsehir Ahi Evran University Training and Research Hospital Ethics Committee and the Republic of Turkey, Ministry of Health (No. 2020-11/92). The study was conducted in accordance with the principles of the Declaration of Helsinki.

A total of 2,960 patients (1.755 males, 1.205 females; mean age: 39.63 years; range, 1 to 98 years) with orthopedic fractures were included in the study: 552 patients during the pandemic period (March $10^{\text {th }}$ and July $\left.1^{\text {st }}, 2020\right)$ and 1,158 patients in the same period 2019 and 1,250 patients in 2018. The patients were divided into two groups as the pandemic group $(\mathrm{n}=552)$ consisting of patients who were admitted in 2020 and the controls group consisting of patients admitted in $2019(n=1,158)$ and $2018(n=1,250)$. The demographic details of patients, the mechanism of injury, location of the fracture, setting where the fracture occurred, concomitant injuries, length of hospital stay, and treatment method were recorded. More than one orthopedic fracture in different locations were categorized as multiple fractures. Fractures distal to the wrist were examined together as hand fractures and fractures distal to ankle joint were analyzed as foot fractures. All periprosthetic fractures were analyzed as a single group. The mechanism of injury was assessed in detail. Injuries that occurred during a new hobby, sports activities, or occupation were labeled as injuries during unfamiliar activities. The proportion of fracture locations, characteristics, demographic variables, injury mechanisms, and treatment modalities were compared between 2018, 2019 , and 2020. The data were analyzed separately for the pediatric ( $<18$ years old), adult ( $\geq 18$ years old), and elderly ( $\geq 70$ years old) populations. We also questioned whether there was a lockdown, when the injury occurred. In Turkey, individuals over 65 and under 18 years of age were not permitted to go outside, with some exceptions in the first peak of the pandemic. Lockdown rules varied according to occupation, city, and whether it was a week or weekend day. Therefore, the lockdown period may differ for everyone.

We classified the fracture mechanism as follows: (i) simple fall indoors, (ii) simple fall outdoors, 


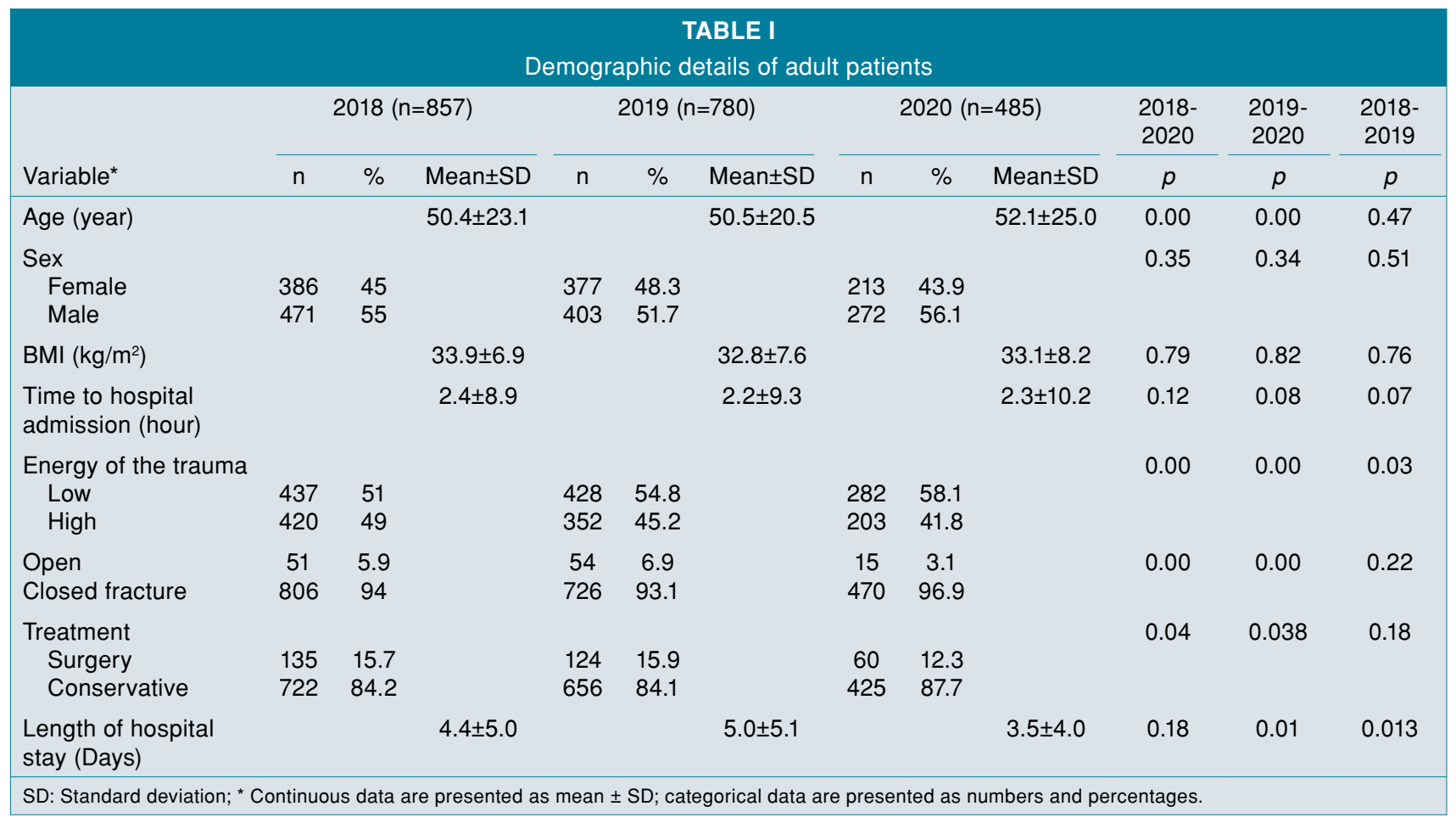

(iii) in-vehicle traffic accident, (iv) out-of-vehicle traffic accident, $(v)$ work accident, (vi) fall from height, (vii) sports trauma, (viii) farm accident, (ix) gunshot, and $(x)$ assault. Falling from standing height or less and minor sports accidents (including ankle sprains) were considered low-energy traumas. Motor-vehicle accidents, fall from height, assaults, gunshots, and industrial and farm accidents were considered high-energy traumas. In addition, fractures were classified as closed or open.

\begin{tabular}{|c|c|c|c|c|c|c|c|c|c|c|c|c|}
\hline \multirow[b]{3}{*}{ Variable* } & \multicolumn{9}{|c|}{$\begin{array}{c}\text { TABLE II } \\
\text { Demographic characteristics of pe }\end{array}$} & \multirow{3}{*}{$\begin{array}{c}2018- \\
2020 \\
p\end{array}$} & \multirow{3}{*}{$\begin{array}{c}2019- \\
2020 \\
p\end{array}$} & \multirow{3}{*}{$\begin{array}{c}2018 \\
2019 \\
p\end{array}$} \\
\hline & \multicolumn{3}{|c|}{$2018(n=393)$} & \multicolumn{3}{|c|}{$2019(n=378)$} & \multicolumn{3}{|c|}{$2020(n=67)$} & & & \\
\hline & $\mathrm{n}$ & $\%$ & Mean $\pm S D$ & $\mathrm{n}$ & $\%$ & Mean $\pm S D$ & $\mathrm{n}$ & $\%$ & Mean $\pm S D$ & & & \\
\hline Age (year) & & & $11.9 \pm 5.0$ & & & $11.2 \pm 4.4$ & & & $9.4 \pm 3.6$ & 0.09 & 0.012 & 0.89 \\
\hline Sex & & & & & & & & & & 0.03 & 0.004 & 0.48 \\
\hline Female & 96 & 24.4 & & 103 & 27.2 & & 30 & 44.8 & & & & \\
\hline Male & 297 & 75.5 & & 275 & 72.8 & & 37 & 55.2 & & & & \\
\hline $\begin{array}{l}\text { Time to hospital } \\
\text { admission (hour) }\end{array}$ & & & $2.3 \pm 17.4$ & & & $2.0 \pm 22.5$ & & & $2.1 \pm 4.9$ & 0.64 & 0.78 & 0.59 \\
\hline Energy of the trauma & & & & & & & & & & 0.005 & 0.006 & 0.28 \\
\hline Low & 216 & 54.9 & & 220 & 58.2 & & 51 & 76.1 & & & & \\
\hline High & 177 & 45 & & 158 & 41.8 & & 16 & 23.9 & & & & \\
\hline Open & 39 & 10 & & 47 & 12.4 & & 1 & 1.5 & & 0.06 & 0.005 & 0.13 \\
\hline Closed fracture & 354 & 90 & & 331 & 87.6 & & 66 & 98.5 & & & & \\
\hline Treatment & & & & & & & & & & 0.72 & 0.76 & 0.67 \\
\hline Surgery & 102 & 25.95 & & 91 & 24.1 & & 15 & 22.4 & & & & \\
\hline Conservative & 291 & 74.04 & & 287 & 75.9 & & 52 & 77.6 & & & & \\
\hline $\begin{array}{l}\text { Length of hospital } \\
\text { stay (Days) }\end{array}$ & & & $2.3 \pm 1.7$ & & & $2.6 \pm 2.3$ & & & $1.8 \pm 1.5$ & 0.43 & 0.17 & 0.21 \\
\hline
\end{tabular}




\section{Statistical analysis}

Statistical analysis was performed using the IBM SPSS for Windows version 22.0 software (IBM Corp., Armonk, NY, USA). Descriptive data were expressed in mean \pm standard deviation (SD), median (min-max) or number and frequency. The Kolmogorov-Smirnov test was performed to analyze the distribution of variables. The t-test and analysis of variance (ANOVA) were used for normally distributed data. The Mann-Whitney U and Kruskal-Wallis tests were performed to compare continuous data between the two or more than two groups, respectively. The chi-square and Fisher exact tests were used in the evaluation of qualitative independent data. A $p$ value of $<0.05$ was considered statistically significant.

\section{RESULTS}

Demographic characteristics of the patients, energy of trauma, time to admission, and treatment modalities of adult and pediatric patients from each year are shown in Tables I and II, respectively. The distributions of fracture locations in the adult and pediatric population are shown in Figure 1 and 2, respectively. The details of the distribution of fractures in the upper and lower extremity in the adult patients are shown in Table III and Table IV, respectively. Pediatric fracture locations in the upper and lower extremity are shown in Table V and VI, respectively. The mechanisms of injury in adult and pediatric

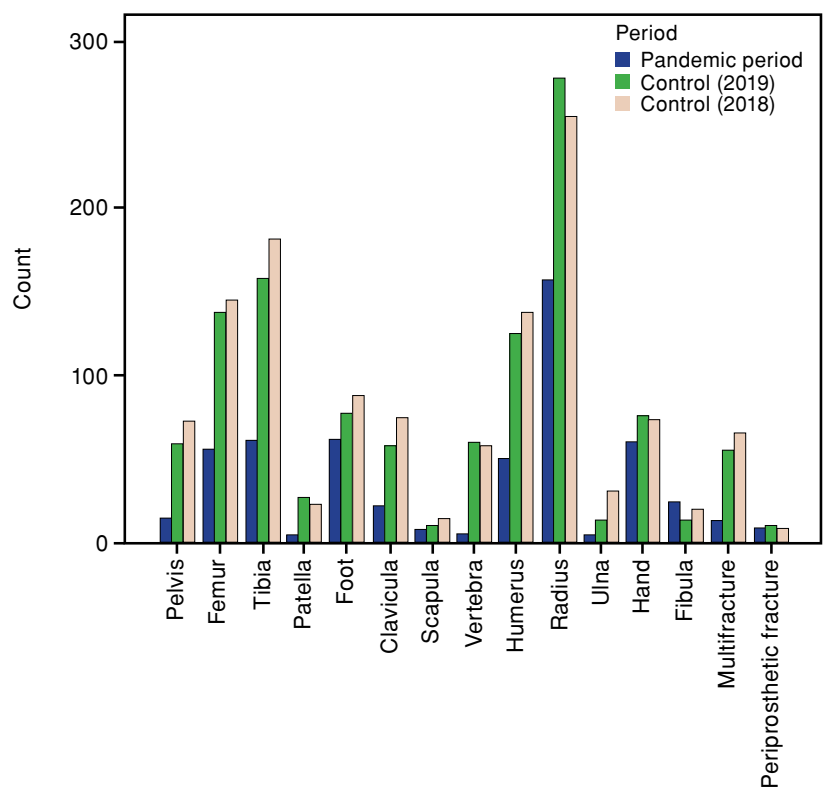

Location populations are presented in Figures 3 and 4. In the adult population, the proportion of home accidents was significantly higher in the pandemic period than in the control period $(48.5 \%$ in 2020, 20.6\% in 2019 and $18.1 \%$ in $2018 \mathrm{p}=0.015)$. The proportion of work accidents $(\mathrm{p}=0.02)$, out-of-vehicle traffic accidents $(p=0.035)$, falls from height $(p=0.038)$, farm accidents $(\mathrm{p}<0.001)$, and gunshots $(\mathrm{p}<0.001)$ significantly decreased during the pandemic period compared to 2018 and 2019. Moreover, in the pandemic period, $18.3 \%$ of the adult injuries occurred during unfamiliar activities, which was significantly higher than what was observed in the control group (18.3\% in 2020, $8.33 \%$ in 2019 and $6.95 \%$ in 2018, $\mathrm{p}<0.001)$.

In the elderly population ( $\geq 70$ years old), the frequency of proximal femoral fractures was similar between pandemic and non-pandemic periods, but the proportion of proximal femoral fractures was significantly increased in the pandemic period compared to 2018 and 2019 ( $\mathrm{n}=32,20.3 \%$ in 2020 vs. $\mathrm{n}=33,15 \%$ in 2019 and $\mathrm{n}=35, \% 14.1$ in 2018 respectively, $\mathrm{p}=0.043$ ). The most common mechanism of injury was simple fall in the bathroom during ablution in the pandemic period $(n=10,31.2 \%)$. This proportion was significantly higher than that in the non-pandemic groups $(31.2 \%$ vs. $15.2 \%, 16.4 \%, \mathrm{p}=0.025)$.

The most frequent etiology for surgery was proximal femoral fracture $(n=35,50.7 \%)$ in the adult population during the pandemic period. In contrast,

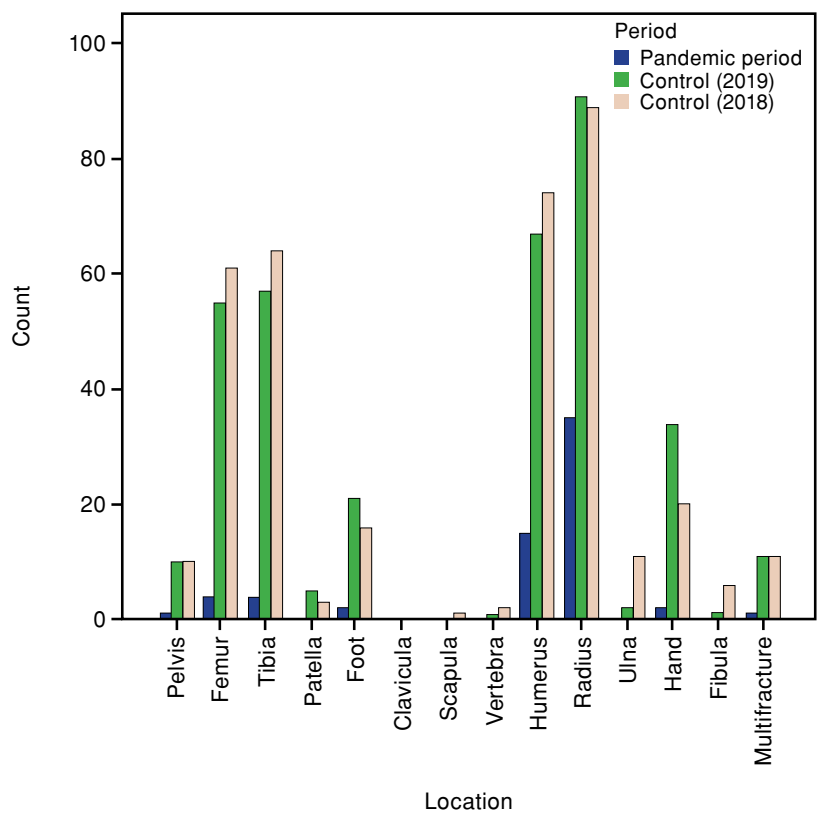

FIGURE 2. Frequencies of fracture locations in the pediatric population during the pandemic and non-pandemic periods. 


\begin{tabular}{|c|c|c|c|c|c|c|c|c|c|}
\hline & & ractur & ations & $\begin{array}{l}\text { ABLE } \\
\text { pper } \epsilon\end{array}$ & ity in & patie & & & \\
\hline & & & & & & & $2018-2020$ & 2019-2020 & 2018-2019 \\
\hline & $\mathrm{n}$ & $\%$ & $\mathrm{n}$ & $\%$ & $\mathrm{n}$ & $\%$ & $p$ & $p$ & $p$ \\
\hline Hand & 54 & 6.3 & 42 & 5.4 & 58 & 12 & 0.052 & 0.037 & 0.89 \\
\hline Carpal & 4 & 0.5 & 2 & 0.3 & 2 & 0.4 & & & \\
\hline Metacarpal & 18 & 2.1 & 14 & 1.8 & 19 & 4 & & & \\
\hline Proximal phalanx & 20 & 2.3 & 17 & 2.2 & 23 & 4.8 & & & \\
\hline Midphalanx & 4 & 0.5 & 3 & 0.4 & 5 & 1 & & & \\
\hline Distal phalanx & 8 & 0.9 & 6 & 0.8 & 9 & 1.9 & & & \\
\hline Forearm & 186 & 21.7 & 198 & 25.4 & 128 & 26.3 & & & \\
\hline Distal & 120 & 14 & 131 & 16.7 & 101 & 20.8 & 0.77 & 0.92 & 0.94 \\
\hline Shaft & 37 & 4.3 & 42 & 5.4 & 17 & 3.5 & 0.89 & 0.82 & 0.86 \\
\hline Proximal & 29 & 3.4 & 25 & 3.2 & 10 & 2 & 0.54 & 0.25 & 0.54 \\
\hline Humerus & 64 & 7.5 & 58 & 7.4 & 35 & 7.2 & & & \\
\hline Distal & 17 & 1.98 & 16 & 2 & 7 & 1.4 & 0.89 & 0.47 & 0.92 \\
\hline Shaft & 22 & 2.56 & 19 & 2.4 & 9 & 1.8 & 0.39 & 0.42 & 0.87 \\
\hline Proximal & 25 & 2.9 & 23 & 2.9 & 19 & 3.9 & 0.35 & 0.38 & 0.99 \\
\hline Clavicula & 50 & 5.8 & 35 & 4.5 & 19 & 3.9 & 0.47 & 0.51 & 0.50 \\
\hline Scapula & 13 & 1.5 & 10 & 12.8 & 8 & 1.6 & 0.92 & 0.83 & 0.88 \\
\hline
\end{tabular}

\begin{tabular}{|c|c|c|c|c|c|c|c|c|c|}
\hline \multicolumn{10}{|c|}{$\begin{array}{l}\text { TABLE IV } \\
\text { le lower extremity and vertebr }\end{array}$} \\
\hline & \multicolumn{2}{|c|}{2018} & \multicolumn{2}{|c|}{2019} & \multicolumn{2}{|c|}{2020} & \multirow{2}{*}{$\frac{2018-2020}{p}$} & \multirow{2}{*}{$\frac{2019-2020}{p}$} & \multirow{2}{*}{$\frac{2018-2019}{p}$} \\
\hline & $\mathrm{n}$ & $\%$ & $\mathrm{n}$ & $\%$ & $\mathrm{n}$ & $\%$ & & & \\
\hline Foot & 72 & 8.4 & 56 & 7.2 & 59 & 12.2 & 0.66 & 0.60 & 0.88 \\
\hline Tarsal & 29 & 3.4 & 25 & 3.2 & 21 & 4.3 & & & \\
\hline Metatarsal & 26 & 3 & 19 & 2.4 & 25 & 5.2 & & & \\
\hline Proximal phalanx & 8 & 0.9 & 6 & 0.8 & 6 & 1.2 & & & \\
\hline Midphalanx & 6 & 0.7 & 2 & 0.3 & 5 & 1 & & & \\
\hline Distal phalanx & 3 & 0.4 & 4 & 0.5 & 2 & 0.4 & & & \\
\hline Tibia-fibula & 132 & 15.4 & 113 & 14.4 & 81 & 16.7 & & & \\
\hline Ankle & 74 & 8.6 & 65 & 8.33 & 61 & 12.5 & 0.78 & 0.77 & 0.92 \\
\hline Shaft & 41 & 4.8 & 39 & 5 & 15 & 3 & 0.60 & 0.52 & 0.95 \\
\hline Platau & 17 & 1.98 & 9 & 1.15 & 5 & 1 & 0.15 & 0.98 & 0.38 \\
\hline Femur & 84 & 9.8 & 83 & 10.6 & 52 & 10.7 & & & \\
\hline Distal & 15 & 1.75 & 16 & 2 & 7 & 1.4 & 0.88 & 0.82 & 0.90 \\
\hline Shaft & 33 & 3.85 & 30 & 3.8 & 10 & 2.1 & 0.75 & 0.78 & 0.96 \\
\hline Proximal & 36 & 4.2 & 37 & 4.7 & 35 & 7.2 & 0.02 & 0.02 & 0.80 \\
\hline Patella & 20 & 2.3 & 22 & 2.8 & 5 & 1 & 0.70 & 0.64 & 0.74 \\
\hline Pelvis & 63 & 7.4 & 49 & 6.3 & 13 & 2.7 & 0.04 & 0.045 & 0.66 \\
\hline Vertebra & 56 & 6.5 & 59 & 7.6 & 6 & 1.2 & 0.03 & 0.02 & 0.88 \\
\hline Multiple fractures & 55 & 6.4 & 45 & 5.8 & 12 & 2.5 & 0.02 & 0.03 & 0.76 \\
\hline Periprosthetic fracture & 8 & 0.93 & 10 & 1.28 & 9 & 1.8 & 0.58 & 0.66 & 0.74 \\
\hline
\end{tabular}




\section{TABLE V}

Fracture locations in the upper extremity in the pediatric patients

\begin{tabular}{|c|c|c|c|c|c|c|c|c|c|}
\hline & \multicolumn{2}{|c|}{2018} & \multicolumn{2}{|c|}{2019} & \multicolumn{2}{|c|}{2020} & \multirow{2}{*}{$\frac{2018-2020}{p}$} & \multirow{2}{*}{$\frac{2019-2020}{p}$} & \multirow{2}{*}{$\frac{2018-2019}{p}$} \\
\hline & $\mathrm{n}$ & $\%$ & $\mathrm{n}$ & $\%$ & $\mathrm{n}$ & $\%$ & & & \\
\hline Hand & 20 & 5.1 & 34 & 9 & 2 & 3 & 0.42 & 0.15 & 0.33 \\
\hline Carpal & 0 & 0 & 1 & 0.3 & 0 & 0 & & & \\
\hline Metacarpal & 4 & 1 & 8 & 2.1 & 0 & 0 & & & \\
\hline Proximal phalanx & 5 & 1.3 & 12 & 3.2 & 1 & 1.5 & & & \\
\hline Midphalanx & 4 & 1 & 5 & 1.3 & 0 & 0 & & & \\
\hline Distal phalanx & 7 & 1.8 & 8 & 2.1 & 1 & 1.5 & & & \\
\hline Forearm & 100 & 25.4 & 93 & 24.6 & 35 & 52.2 & & & \\
\hline Distal & 59 & 15 & 60 & 15.8 & 28 & 41.8 & 0.001 & 0.001 & 0.90 \\
\hline Shaft & 28 & 7.12 & 25 & 6.6 & 6 & 9 & 0.52 & 0.36 & 0.68 \\
\hline Proximal & 13 & 3.3 & 8 & 2.1 & 1 & 1.5 & 0.40 & 0.48 & 0.44 \\
\hline Humerus & 74 & 18.8 & 67 & 17.7 & 15 & 22.4 & & & \\
\hline Distal & 47 & 11.9 & 53 & 14 & 11 & 16.4 & 0.58 & 0.50 & 0.74 \\
\hline Shaft & 12 & 3 & 7 & 1.8 & 2 & 3 & 0.98 & 0.16 & 0.98 \\
\hline Proximal & 15 & 3.8 & 11 & 2.9 & 2 & 3 & 0.83 & 0.92 & 0.59 \\
\hline Clavicula & 25 & 6.4 & 23 & 6.1 & 3 & 4.5 & 0.72 & 0.75 & 0.87 \\
\hline Scapula & 1 & 0.3 & 0 & 0 & 0 & 0 & 0.33 & 1 & 0.68 \\
\hline
\end{tabular}

TABLE VI

Fracture locations in the lower extremity and vertebra in the pediatric patients

\begin{tabular}{|c|c|c|c|c|c|c|c|c|c|}
\hline & \multicolumn{2}{|c|}{2018} & \multicolumn{2}{|c|}{2019} & \multicolumn{2}{|c|}{2020} & \multirow{2}{*}{$\frac{2018-2020}{p}$} & \multirow{2}{*}{$\frac{2019-2020}{p}$} & \multirow{2}{*}{$\frac{2018-2019}{p}$} \\
\hline & $\mathrm{n}$ & $\%$ & $\mathrm{n}$ & $\%$ & $\mathrm{n}$ & $\%$ & & & \\
\hline Foot & 16 & 4.1 & 21 & 5.6 & 2 & 3 & 0.56 & 0.26 & 0.88 \\
\hline Tarsal & 1 & 0.3 & 2 & 0.5 & 0 & 0 & & & \\
\hline Metatarsal & 4 & 1 & 6 & 1.6 & 1 & 1.5 & & & \\
\hline Proximal phalanx & 6 & 1.5 & 8 & 2.1 & 1 & 1.5 & & & \\
\hline Midphalanx & 3 & 0.8 & 2 & 0.5 & 0 & 0 & & & \\
\hline Distal phalanx & 2 & 0.5 & 3 & 0.8 & 0 & 0 & & & \\
\hline Tibia-fibula & 70 & 17.8 & 58 & 15.5 & 3 & 4.5 & 0.02 & 0.03 & 0.92 \\
\hline Distal & 31 & 7.88 & 26 & 6.9 & 2 & 3 & & & \\
\hline Shaft & 34 & 8.65 & 29 & 7.7 & 1 & 1.5 & & & \\
\hline Proximal & 5 & 1.27 & 3 & 0.8 & 0 & 0 & & & \\
\hline Femur & 61 & 15.5 & 55 & 14.6 & 5 & 7.5 & 0.052 & 0.06 & 0.91 \\
\hline Distal & 30 & 7.63 & 21 & 5.5 & 2 & 3 & & & \\
\hline Shaft & 34 & 8.65 & 29 & 7.6 & 2 & 3 & & & \\
\hline Proximal & 7 & 1.78 & 5 & 1.3 & 1 & 1.5 & & & \\
\hline Patella & 3 & 0.8 & 5 & 1.3 & 0 & 0 & 0.13 & 0.09 & 0.54 \\
\hline Pelvis & 10 & 2.5 & 10 & 2.6 & 1 & 1.5 & 0.76 & 0.72 & 0.97 \\
\hline Vertebra & 2 & 0.5 & 1 & 0.3 & 0 & 0 & 0.36 & 0.41 & 0.72 \\
\hline Multiple fractures & 11 & 2.8 & 11 & 2.9 & 1 & 1.5 & 0.64 & 0.62 & 0.88 \\
\hline
\end{tabular}




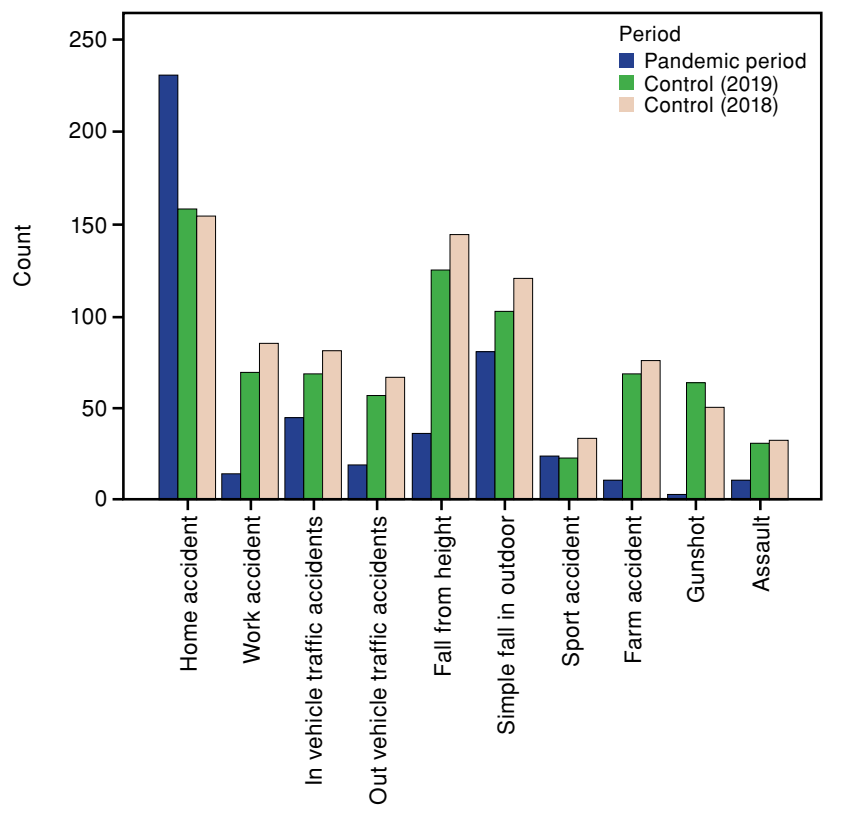

Mechanism

FIGURE 3. Injury mechanisms of the adult patients during the pandemic period and non-pandemic periods.

malleolar fractures $(\mathrm{n}=20,16.1 \%$ in 2019 and $\mathrm{n}=24$, $17.7 \%$ in 2018) and forearm fractures $(n=18,14.5 \%$ in 2019 and, $\mathrm{n}=24,19.3 \%$ in 2018) were the two most frequent etiologies for surgery in the adult population, in the control periods. The most common open fractures were hand fractures in both pandemic and nonpandemic periods.

In the pediatric population, during the pandemic period, admissions decreased to approximately $17 \%$ of the 2019 and 2018 (67 vs. 378 and 393, respectively). Distal humeral fracture was the most common etiology for surgery in both the pandemic and control groups.

In the pandemic period, $126(25.9 \%)$ adult injuries occurred during the lockdown period. The most common fracture locations during lockdown were the distal radius, hand, and proximal femur $(24.7 \%, 19.8 \%$, and $17.3 \%$, respectively).

\section{DISCUSSION}

The principal finding of this study was that the proportion of elderly proximal femoral fractures significantly increased during the pandemic period. Consequently, the most frequent orthopedic surgery was for proximal femoral fractures. The proportion of minor home accidents as an injury mechanism also increased during the pandemic period.

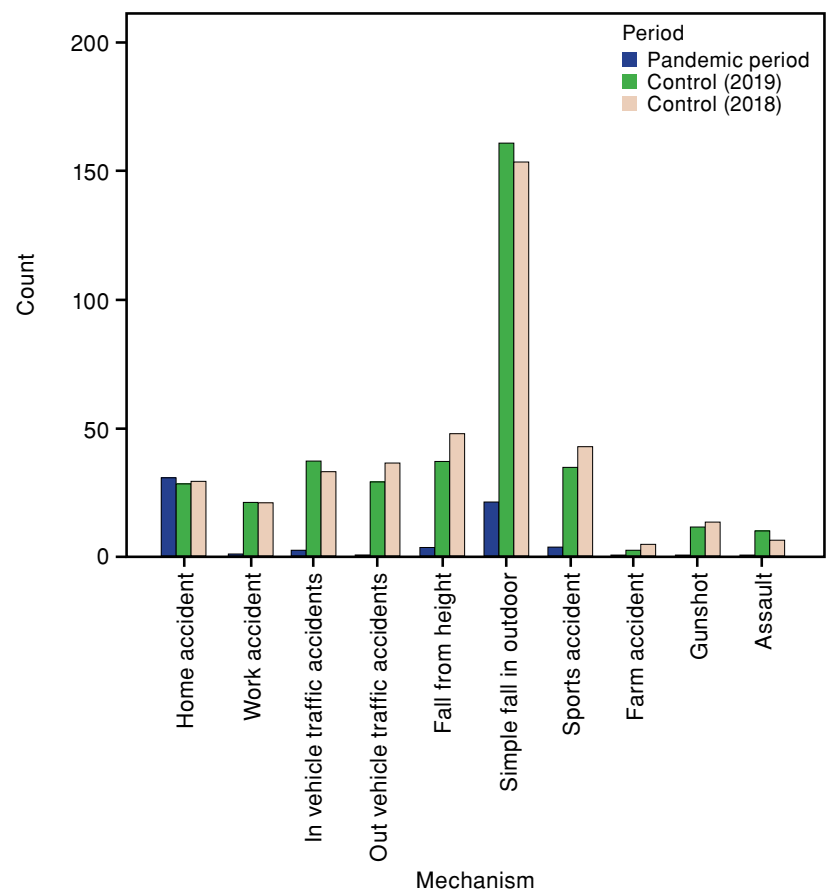

FIGURE 4. Injury mechanisms of the pediatric patients during the pandemic period and non-pandemic periods.

At the time of writing this paper, COVID-19 spread almost all around the world. ${ }^{[12]}$ Similar to numerous other authorities, the Turkish government took various precautions to prevent the spread of the infection. Daily life dramatically changed after restrictions. Large numbers of professionals started working from home, traveling between cities was restricted, and lockdown was applied for people older than 65 years or younger than 18 years in the first peak of the pandemic. As expected, in the pandemic period, the number of orthopedic fractures was less than half of that from the nonpandemic period, in our study. Lv et al. ${ }^{[7]}$ reported a similar ratio in their study (865 patients in the pandemic period and 1,624 in the control period). In our study, the mean age of adult patients was significantly higher in the pandemic period. In a study, however, Turgut et al. ${ }^{[11]}$ found no significant difference between the mean ages of patients in the two groups. Unlike these findings, in another study, the mean age of the patients was higher in the pandemic period, as well. ${ }^{[7]}$ Zhu et al. ${ }^{[13]}$ evaluated the epidemiological characteristics of traumatic fractures in elderly patients during the pandemic period, and found that $58.3 \%$ of the patients sustained a hip fracture, while $72.7 \%$ of all fractures occurred at home. In our study, most of the injuries during the pandemic period occurred at home. Therefore, the 
number of osteoporotic low-energy fractures did not decrease, whereas other major traumas, such as work accidents, gunshots, and traffic accidents, decreased significantly. This is a likely explanation for the proportional decrease in open fractures in both the pediatric and adult populations.

The proportion of pelvis, patella, and vertebral fractures also significantly decreased, and the proportion of proximal femur and hand fractures increased in the adult population during the pandemic period. These results can be also explained by the decreased mobility of people during the pandemic period. Although high-energy traumas decreased during the pandemic period, adult hip fractures did not decrease. In addition, the proportion of pediatric fractures, except for the distal radius, was similar. Therefore, the surgical treatment rates did not change between the pandemic and non-pandemic periods. We observed that the duration of hospital stay was significantly reduced during the pandemic period. Based on these findings, we can speculate that a decrease in high-energy trauma and open fracture rates may result in shorter hospital stays during the pandemic period. Prolonged hospital stay may cause nosocomial spread of COVID-19, and faster circulation of patients is needed, as the capacity of orthopedic clinics is reduced during the pandemic period.

The most common osteoporotic fractures are seen in the distal radius, proximal humerus, vertebra, and proximal femur. ${ }^{[14,15]}$ The majority of fractures can be treated conservatively, except for proximal femoral fractures. ${ }^{[16-20]}$ Proximal femoral fractures are associated with high rates of mortality and morbidity. ${ }^{[21,22]}$ During the pandemic period, elderly hip fractures pose a burden on the healthcare system. A proportional increase in elderly hip fractures was reported during the pandemic period, ${ }^{[7,23]}$ which is consistent with the findings of the present study. Elderly patients have a higher mortality rate after COVID-19, ${ }^{[24,25]}$ and the risk of nosocomial COVID-19 is an important concern in this population. Preventative measures to reduce hip fractures have become more important during the pandemic period.

In our study, in the elderly population, the most common etiology of proximal femoral fracture was falling during ablution (31.2\%). Taking ablution is a Muslim ceremony before praying, which consists of washing the face, neck, hands, and feet. The resulting slippery ground may lead to falling during this process. In a recent study, ${ }^{[26]}$ slippery floors were reported as the most common cause of falls among the elderly population in both rural and urban areas. We suggest warning individuals to prevent falls, while taking ablution. As most home accidents result from environment-related factors, ${ }^{[27]}$ taking simple precautions at home may help to reduce falls, such as wearing slippers, placing carpets in the bathroom, and illuminating the corridors and bathroom at night. In addition, in-home exercise programs have been shown to be beneficial in reducing falls in the elderly population. ${ }^{[28]}$ The prescription of individualized home-based strengthening and balance exercises may be suggested during lock-down periods. Discontinuation of denosumab increases the risk of osteoporotic fractures. ${ }^{[29]} \mathrm{Yu}$ et al. ${ }^{[30]}$ recommended switching to bisphosphonates, if continuing denosumab is not possible. In addition, vitamin D and calcium supplementation and indoor sunlight exposure are simple and reliable measures to protect bone mass. ${ }^{[3]}$ Family physicians and filiation teams may play a role in regulating and providing antiosteoporosis treatment to the patients in the risk group to keep the patients at home during the pandemic period.

Starting a new hobby was common in patients who started to spend more time at home. During the pandemic period, $18.5 \%$ of the fractures occurred after unfamiliar activities. To reduce contact with individuals from outside, some started to perform carpentry work, repair, and other housework individually. These new habits may increase home accidents, as well. The proportion of hand fractures (12\%) significantly increased during the pandemic period, which may be explained by these home accidents.

Closing schools and restricting sport activities and common areas affected the daily life of children, as well. Bram et al. ${ }^{[32]}$ reported $60 \%$ reduction in admissions due to fractures in the pandemic period and an increased proportion of home and bicycle accidents. In our study, the reduction in pediatric cases was more than that reported in the literature. Moreover, the proportion of tibial fractures decreased and distal forearm fractures increased during the pandemic period. The Turkish Government implemented strict lockdown for the pediatric population. Therefore, the reduction of admissions during the pandemic period was higher. All minor or major traumas caused by outdoor activities decreased in the pandemic period, and distal humeral fractures were the most frequent surgical indication for pediatric patients. Our findings were consistent with the previous studies. ${ }^{[11,23]}$ Distal humeral fractures remained the most frequent etiology for surgery in the pediatric population. Similar studies. ${ }^{[1,32]}$ reported a decrease 
in the mean age of pediatric patients during the pandemic period, which is consistent with our findings. In addition, the proportion of female patients increased during the pandemic. A decrease in sports injuries may explain this situation, which are more common in adolescent boys.

In the present study, time to hospital admission did not change during the pandemic period. It seems that patients suffering from orthopedic fractures could reach healthcare services without any difficulties. Canceling all elective operations was a rational solution at the beginning of the pandemic period. However, as the duration of the pandemic is longer than expected, the treatment of patients other than fracture remains a concern in the orthopedic practice. Some authors ${ }^{[33-35]}$ have suggested that new treatment guidelines should be created during the pandemic period for different subspecialties, such as pediatric orthopedics, orthopedic oncology, and shoulder and elbow surgery.

To the best of our knowledge, this is the first large-scale, multi-center study to evaluate the epidemiological characteristics of orthopedic fractures in the Turkish population during the COVID-19 outbreak. Our findings may help orthopedic surgeons to be prepared to handle different patient populations during the pandemics, as the daily life is completely different than normal. Nonetheless, this study has several limitations that should be noted. First, we evaluated 110 days for each year; however, it seems that the pandemics last for a long time and, therefore, our findings may not be representative of the entire pandemic period, which is not under control yet. On the other hand, we cover a longer time in this study than previous studies. Thus, our data may be more representative for the pandemic period. Second, our population was relatively small. We obtained data from three different hospitals. The first center is a high-volume state hospital from a crowded city, the second is a tertiary referral hospital between the eastern part of the country and the capital, and the third is a state hospital which mostly serves patients from a rural area. The epidemiological characteristics of provinces affect the profile of patients in orthopedic practice, since patient demographics may change in different cities. Including data from more centers from different parts of the country may increase the generalizability of the findings in the future. Third, we used ICD-10 codes and patient files to select patients for the study. We may have missed some of the patients due to incomplete medical records. Fourth, we decided whether it was a fragility fracture or not according to trauma energy and patient age. Meanwhile, we may have misclassified some patients with osteoporosis at younger ages. Fifth, we did not analyze whether those patients were infected with COVID-19. Finally, this was a retrospective study, and we may not be able to detect all fractures during the relevant periods. Future studies should be designed to evaluate the impact of COVID-19 in patients with orthopedic fractures and the prognosis of orthopedic patients with COVID-19.

In conclusion, adult proximal femoral and hand fractures and pediatric distal forearm fractures showed a proportional increase during the pandemic period, and the most frequent setting where the fracture occurred was the home. In the light of these findings, orthopedic surgeons must be prepared for elderly patients with fragility fractures. Taking preventative measures to reduce in-home accidents and to provide effective in-home measures to prevent osteopenia may be beneficial for decreasing the number of fragility fractures and home accident-related fractures in future pandemics.

\section{Declaration of conflicting interests}

The authors declared no conflicts of interest with respect to the authorship and/or publication of this article.

\section{Funding}

The authors received no financial support for the research and/or authorship of this article.

\section{REFERENCES}

1. Zhu N, Zhang D, Wang W, Li X, Yang B, Song J, et al. A Novel Coronavirus from patients with pneumonia in China, 2019. N Engl J Med 2020;382:727-33.

2. Cucinotta D, Vanelli M. WHO declares COVID-19 a pandemic. Acta Biomed 2020;91:157-60.

3. Cakir B. COVID-19 in Turkey: Lessons learned. J Epidemiol Glob Health 2020;10:115-7.

4. Demirbilek Y, Pehlivantürk G, Özgüler ZÖ, Alp Meşe E. COVID-19 outbreak control, example of ministry of health of Turkey. Turk J Med Sci 2020;50:489-94.

5. Narici M, De Vito G, Franchi M, Paoli A, Moro T, Marcolin $\mathrm{G}$, et al. Impact of sedentarism due to the COVID-19 home confinement on neuromuscular, cardiovascular and metabolic health: Physiological and pathophysiological implications and recommendations for physical and nutritional countermeasures. Eur J Sport Sci 2020:1-22.

6. Atik OŞ. Elective surgeries during COVID-19 storm: The best surgeon knows when not to operate. Jt Dis Relat Surg 2020;31:161-2.

7. Lv H, Zhang Q, Yin Y, Zhu Y, Wang J, Hou Z, et al. Epidemiologic characteristics of traumatic fractures during the outbreak of coronavirus disease 2019 (COVID-19) in China: A retrospective \& comparative multi-center study. Injury 2020;51:1698-704.

8. Cauley JA, Cawthon PM, Peters KE, Cummings SR, Ensrud $\mathrm{KE}$, Bauer DC, et al. Risk factors for hip fracture in older 
men: The osteoporotic fractures in men study (MrOS). J Bone Miner Res 2016;31:1810-9.

9. Curtis EM, Moon RJ, Harvey NC, Cooper C. The impact of fragility fracture and approaches to osteoporosis risk assessment worldwide. Bone 2017;104:29-38.

10. Slullitel PA, Lucero CM, Soruco ML, Barla JD, Benchimol JA, Boietti BR, et al. Prolonged social lockdown during COVID-19 pandemic and hip fracture epidemiology. Int Orthop 2020;44:1887-95.

11. Turgut A, Arlı H, Altundağ Ü, Hancioğlu S, Egeli E, Kalenderer Ö. Effect of COVID-19 pandemic on the fracture demographics: Data from a tertiary care hospital in Turkey. Acta Orthop Traumatol Turc 2020;54:355-63.

12. Ge H, Wang X, Yuan X, Xiao G, Wang C, Deng T, et al. The epidemiology and clinical information about COVID-19. Eur J Clin Microbiol Infect Dis 2020;39:1011-9.

13. Zhu Y, Chen W, Xin X, Yin Y, Hu J, Lv H, et al. Epidemiologic characteristics of traumatic fractures in elderly patients during the outbreak of coronavirus disease 2019 in China. Int Orthop 2020;44:1565-70.

14. Warriner AH, Patkar NM, Curtis JR, Delzell E, Gary L, Kilgore $\mathrm{M}$, et al. Which fractures are most attributable to osteoporosis? J Clin Epidemiol 2011;64:46-53.

15. Cauley JA. Osteoporosis: Fracture epidemiology update 2016. Curr Opin Rheumatol 2017;29:150-6.

16. Schumaier A, Grawe B. Proximal humerus fractures: Evaluation and management in the elderly patient. Geriatr orthop surg rehabil 2018;9:2151458517750516.

17. Stone MA, Namdari S. Surgical considerations in the treatment of osteoporotic proximal humerus fractures. Orthop Clin North Am 2019;50:223-31.

18. Rajasekaran S, Kanna RM, Schnake KJ, Vaccaro AR, Schroeder GD, Sadiqi S, et al. Osteoporotic thoracolumbar fractures-how are they different?-Classification and treatment algorithm. J Orthop Trauma 2017;31 Suppl 4:S49-S56.

19. Luokkala T, Laitinen MK, Hevonkorpi TP, Raittio L, Mattila VM, Launonen AP. Distal radius fractures in the elderly population. EFORT Open Rev 2020;5:361-70.

20. Roberts KC, Brox WT, Jevsevar DS, Sevarino K. Management of hip fractures in the elderly. J Am Acad Orthop Surg 2015;23:131-7.

21. Nkanang B, Parker M, Parker E, Griffiths R. Perioperative mortality for patients with a hip fracture. Injury 2017;48:2180-3.

22. Guzon-Illescas O, Perez Fernandez E, Crespí Villarias N, Quirós Donate FJ, Peña M, Alonso-Blas C, et al. Mortality after osteoporotic hip fracture: Incidence, trends, and associated factors. J Orthop Surg Res 2019;14:203.
23. Carkci E, Polat B, Polat A, Peker B, Öztürkmen Y. The Effect of the Coronavirus 2019 (COVID-19) pandemic on the number and characteristics of orthopedic trauma patients in a tertiary care hospital in Istanbul. Cureus 2021;13:e12569.

24. Wu Z, McGoogan JM. Characteristics of and important lessons from the coronavirus disease 2019 (COVID-19) outbreak in China: Summary of a report of 72314 cases from the Chinese Center for Disease Control and Prevention. JAMA 2020;323:1239-42.

25. Liu K, Chen Y, Lin R, Han K. Clinical features of COVID-19 in elderly patients: A comparison with young and middleaged patients. J Infect 2020;80:e14-e18.

26. Kim M, Chang M, Nam E, Kim SG, Cho SI, Ryu DH, et al. Fall characteristics among elderly populations in urban and rural areas in Korea. Medicine (Baltimore) 2020;99:e23106.

27. Rubenstein LZ. Falls in older people: Epidemiology, risk factors and strategies for prevention. Age Ageing 2006;35 Suppl 2:ii37-ii41.

28. Boongird C, Keesukphan P, Phiphadthakusolkul S, Rattanasiri S, Thakkinstian A. Effects of a simple homebased exercise program on fall prevention in older adults: A 12-month primary care setting, randomized controlled trial. Geriatr Gerontol Int 2017;17:2157-63.

29. Anastasilakis AD, Polyzos SA, Makras P, Aubry-Rozier B, Kaouri S, Lamy O. Clinical features of 24 patients with rebound-associated vertebral fractures after denosumab discontinuation: Systematic review and additional cases. J Bone Miner Res 2017;32:1291-6.

30. Yu EW, Tsourdi E, Clarke BL, Bauer DC, Drake MT. Osteoporosis management in the era of COVID-19. J Bone Miner Res 2020;35:1009-13.

31. Zou J, Song DW, Niu JJ, Shi JW, Yang HL. Standardized outpatient diagnosis and treatment process for osteoporosis clinics during the COVID-19 pandemic. Eur Rev Med Pharmacol Sci 2020;24:5778-82.

32. Bram JT, Johnson MA, Magee LC, Mehta NN, Fazal FZ, Baldwin KD, et al. Where have all the fractures gone? The epidemiology of pediatric fractures during the COVID-19 pandemic. J Pediatr Orthop 2020;40:373-9.

33. Şahbat Y, Buyuktopcu O, Topkar OM, Erol B. Management of orthopedic oncology patients during coronavirus pandemic. J Surg Oncol 2020:10.1002/jso.26092.

34. Birsel O, Eren İ, Demirhan M. How the Covid-19 pandemic affected shoulder and elbow practice in Turkey? JSES Int 2020;4:705-708.e2.

35. Birsel SE, Sarıkaya İA, Şeker A, Erdal OA, Görgün $\mathrm{B}$, Inan M. How the COVID-19 pandemic is affecting paediatric orthopaedic practice in Turkey. J Child Orthop 2020;14:581-8. 